Т.Ю. Маркова*

\title{
ПОСТАНОВКА ВОПРОСОВ ПРИСЯЖНЫМ ЗАСЕДАТЕЛЯМ ПО УСТАВУ УГОЛОВНОГО СУДОПРОИЗВОДСТВА 1864 ГОДА
}

Аннотация: В статье выделяется различие между англо-американской и континентальной системой постановки вопросов присяжным заседателям; рассматриваются причины введения в российский уголовный процесс этапа постановки вопросов коллегии присяжных и описываются положительные и отрицательные стороны введения данного этапа судебного разбирательства. Анализируется основание постановки вопросов присяжным заседателям, право сторон и суда, случаи и порядок изменения выводов обвинительного акта, а также последствия несоблюдения установленного порядка изменения предъявленного подсудимому обвинения. Приводятся позиции дореволюционных юристов о том, каким образом судебное следствие и заключительные прения могут изменить или дополнить выводы обвинительного акта. Делается ссылка на постановления Кассационного Сената, который давал судам руководящие разъяснения о том, как следует разрешать несоответствие между некоторыми признаками преступного деяния, изложенными в обвинительном акте, и признаками этого же деяния, закрепленными в уголовном законе. Определяются и раскрываются требования к содержанию и формулировкам вопросов, которые ставились перед коллегией присяжных, указываются случаи, при которых запрещалось соединение различных вопросов в один общий. В конце статьи рассматривается право сторон и присяжных заседателей ходатайствовать о дополнении и изменении вопросного листа, а также полномочия суда, связанные с поступившими ходатайствами.

Ключевые слова: Устав уголовного судопроизводства, присяжные заседатели, вопросный лист, основания постановки вопросов, изменение обвинения, смягчение ответственности, усиление ответственности, порядок постановки вопросов, изменение вопросного листа, Кассационный Сенат.

DOI: 10.7256/1994-1471.2014.4.10997

$\mathrm{B}$ отличие от англо-американской модели суда присяжных, в которой перед коллегией заседателей вопросы не ставятся, в континентальной системе постановка вопросов четко отграничена от судебного следствия, прений сторон и вынесения приговора и является самостоятельным этапом судебного разбирательства.

Идея постановки вопросов возникла во Франции и была принята во всех континентальных государствах, где существовал суд присяжных. Закреплению и развитию, в том числе и в России, предварительной постановки вопросов, по мнению Духовского М.В., способствовали две основные причины. Первая была вызвана «крутым и резким переходом от бумажного, розыскного процесса к устному и гласному», а вторая - желанием «со стороны официальных представителей влиять»на принятие решения присяжными заседателями ${ }^{11}$.

Обе причины вполне понятны. В период введения в действие Устава Уголовного Судопроизводства 1864 г. для России был новым не только отдельно суд присяжных, но и весь состязательный процесс в целом. Происходила коренная ломка устоявшихся, вековых норм, правил и традиций, радикально менялось действующее законодательство, крепостные, став свободными гражданами, приобретали определенные права и обязанности, их допускали к отправлению правосудия. В таких условиях довольно трудно было понять, будут ли способны профессиональные юристы работать по новым правилам состязательного процесса,

1 Духовский М.В. Русский уголовный процесс. М., 1902. С. $367-368$.

(C) Маркова Татьяна Юрьевна

Кандидат юридических наук, старший преподаватель кафедры уголовно-процессуального права, Московский государственный юридический университет имени О.Е. Кутафина (МГЮА)

[tatjana_markova@mail.ru]

123995, Россия, г. Москва, ул. Садовая-Кудринская, д. 9. 
а уж присяжным заседателям многие заранее пророчили провал в выполнении возложенной на них функции. Кроме того, необходимо было учитывать опасения, высказываемые по поводу того, что установление суда присяжных в России преследует политические цели. Все это и привело к тому, что была введена обязательная процедура постановки вопросов суду присяжных заседателей как средство удерживать его в нужных рамках и давать ему желательное направление развития.

Английские юристы-практики того времени возражали против подобной системы вынесения присяжными своего вердикта, потому что считали, что она влечет за собой множество недоразумений. Они ссылались на то, что эта система сосредотачивает в руках председательствующего судьи слишком большую власть и что от постановки вопросов очень часто зависит осуждение или оправдание подсудимого.

По мнению К.Ю. Миттермайера, «если в какой-либо стране господствует система, на основании которой присяжным предлагаются вопросы об одних фактах, то жюри легко может быть введено в обман, потому что присяжные часто не могут отвечать отрицательно на вопросы о фактах, например, если обвиняемый присвоил себе какую-нибудь чужую вещь или употребил какие-нибудь слова; но из этого еще не следует, чтобы в первом случае подсудимый был виновен в воровстве, а во втором - в оскорблении...

...Известно, с какой ловкостью французский государственный адвокат настаивает иногда на опущении какого-нибудь слова, потому что он надеется, что в таком случае присяжные скорее произнесут вердикт о виновности, тогда как защитник настаивает на сохранении этого слова, рассчитывая на то, что это обстоятельство заставит присяжных признать подсудимого невиновным. Сколько споров возбуждает также постановка дополнительных вопросов на случай неудовлетворительного разрешения главного, например, если в главном вопросе дело идет о преднамеренном убийстве, а в дополнительном спрашивается, не нанес ли подсудимый смерти по неосторожности. Государственный адвокат требует постановки такого дополнительного вопроса в надежде, что, по крайней мере, второй вопрос будет разрешен утвердительно; между тем, защитник старается отклонить дополнительный вопрос, рассчитывая на то, что подсудимый в таком случае будет совершенно оправдан, потому что присяжные, будучи поставлены в необходимость решить только главный вопрос о смертоубийстве, скорее признают подсудимого невиновным. Весьма справедливо английские юристыпрактики обращают внимание также на то, что во Франции ежегодно отменяется множество приговоров вследствие неправильной постановки вопросов, что весьма вредно для отправления правосудия» ${ }^{22}$.

Но несмотря на то, что данный этап судебного разбирательства многие юристы рассматривали в качестве средства воздействия на присяжных заседателей, большинство все же признавало, что «обряд постановки вопросов имеет много и хороших сторон». В.Д. Спасович считал, что «он, приручая состязающиеся стороны к самодеятельности, не сопряжен с потерей времени, напротив того, облегчает работу суда, который, удалившись в совещательную комнату, без совершения этого обряда должен был бы приступать к решению дела, начав с него же, т.е. с уяснения себе в последовательном порядке вопросов, подлежащих решению» ${ }^{33}$.

Фойницкий И.Я. выделял и такое достоинство системы отдельных вопросов, как оказание помощи коллегии присяжных заседателей в выполнении возложенной на нее задачи. $\mathrm{OH}$ считал, что благодаря вопросному листу присяжным гораздо легче дать свой ответ, особенно в случае изменения обвинения на судебном следствии ${ }^{44}$.

Устав Уголовного Судопроизводства 1864 г. (далее - УУС) содержал главу девятую «0 порядке постановления и объявления приговоров». Эта глава довольно подробно регламентировала процедуру постановки вопросов и закрепляла виды вопросов, которые могут быть или должны быть поставлены перед коллегией присяжных заседателей.

В соответствии со ст. 751 УУС основанием вопросов по существу дела должны были служить не только выводы обвинительного акта, но также судебное следствие и заключительные прения, в чем они развивали, дополняли или изменяли эти выводы. Обстоятельства же и соображения, изложенные только в заключительных прениях и не подкрепленные никакими доводами, почерпнутыми из судебного следствия, не могли рассматриваться в качестве обоснования требования стороны о постановке вопроса, не соответствующего обвинительному акту.

Обвинительный акт «признавался главным основанием для вопросов не только из-за состязательного характера процесса, но и пото-

2 Миттермайер К.М. Уголовное судопроизводство Англии, Шотландии и Северной Америки. М., 1864. C. $356-357$.

3 Цит. по: Духовский М.В. Указ. соч. С. 368.

4 Фойницкий И.Я. Курс уголовного судопроизводства. - С. - П.: Издательство «АЛЬФА», 1996. В 2 т. Т. 2. C. 449 . 
му, что обвинительный акт был рассмотрен и утвержден высшей судебной инстанцией - камерой предания суду. Он служил основой и в случаях отказа прокурора от обвинения или признания подсудимым своей вины» ${ }^{55}$. Если результаты судебного следствия совпадали с выводами предварительного, то прокурор мог требовать постановки вопросов по обвинительному акту, а отказ суда от удовлетворения такого требования признавался существенным нарушением ст. 751 УУС и служил основанием для отмены приговора.

Однако суд был вправе, вопреки мнению государственного обвинителя, признать, что судебное следствие изменило выводы, изложенные в обвинительном акте, и наряду с вопросом по обвинительному акту поставить вопрос по собственному усмотрению, если обстоятельства, устанавливаемые данным вопросом, имели непосредственное отношение к рассматриваемому делу и порождали определенные юридические последствия.

К сожалению, УУС не содержал норм, которыми следовало бы руководствоваться суду в том случае, когда возникало требующее разрешения несоответствие между некоторыми признаками преступного деяния, изложенными в обвинительном акте, и признаками этого же деяния, закрепленными в уголовном законе. Однако данный пробел был восполнен практикой Кассационного Сената, который в своих постановлениях дал следующие разъяснения:

1) постановку вопросов по фактическим признакам в обвинительном акте суд может изменить в вопросах сообразно существу того обвинения и закона, под действие которого оно подводится, т.к. ст. 751 УУС не требует буквального повторения в вопросах выводов обвинительного акта, которые должны служить лишь основанием для постановки вопросов;

2) при несогласии изложенных в выводе обвинительного акта фактических данных с указанным в том же выводе уголовным законом суд вправе при постановке присяжным заседателям вопроса о виновности принять в основание обстоятельства, помещенные в окончательном выводе обвинительного акта, а не закрепленные в статье Уложения о наказаниях, не соответствующей описанным обстоятельствам;

3) если по обвинительному акту для вменения определенного состава преступления недостает некоторых признаков его, и когда деяния, соответствующие этим недостаю-

Радутная Н.В. Суд присяжных (исторические, социальные и правовые аспекты): Учебное пособие. М., 1991. C. 33-34. щим признакам, не обнаружены и на судебном следствии, то суд не обязан дополнять вопрос о виновности такими признаками, чтобы в случае утвердительного ответа присяжных была возможность применить указанные в обвинительном акте статьи уголовного закона;

4) в-четвертых, неуказание в окончательном выводе обвинительного акта всех признаков того преступного деяния, в котором подсудимый обвиняется, не может служить основанием к отказу в ходатайстве прокурора о дополнении поставленного судом вопроса по признаку преступления, указанного в обвинительном акте, если ходатайство прокурора опирается на изложенные в обвинительном акте фактические обстоятельства;

5) если в обвинительном акте указаны только общие признаки преступления, предусмотренного указанной в нем статьей уголовного закона, состоящей из нескольких пунктов, то суд обязан поместить в вопрос те определяющие виновность подсудимого обстоятельства, которые соответствуют признакам одного из преступлений, закрепленных в пунктах статьи ${ }^{66}$.

На вопрос о том, каким образом судебное следствие и заключительные прения могут изменить или дополнить выводы обвинительного акта, дореволюционные юристы отвечали по-разному. Например, М.В. Духовский считал, что это может произойти в следующих случаях ${ }^{77}$ :

а) когда на судебном следствии обнаруживается преступное деяние, не предусмотренное в обвинительном акте.

Согласно ст. 752 УУС о таком деянии вопросы не предлагались, если по уголовному закону оно подвергалось наказанию более строгому, чем указанное в обвинительном акте. Тогда дело направлялось вновь на предварительное следствие (если это было необходимо) для составления обвинительного акта по всем преступным деяниям подсудимого.

Ст. 752 УУС применялась лишь тогда, когда при рассмотрении уголовного дела, вследствие сознания подсудимого или иного обстоятельства, против этого подсудимого возникало другое, самостоятельное и более тяжкое обвинение, чем то, за которое он привлекался к суду. Кроме того, этой нормой суд руководствовался и при изменении на судебном следствии

\footnotetext{
Устав Уголовного Судопроизводства с позднейшими узаконениями, законодательными мотивами, разъяснениями Правительствующего Сената и циркулярами Министра Юстиции / под ред. Шрамченко М.П. и Широкова В.П. С. - П., 1913. С. 730-731.
}

Духовский М.В. Указ. соч. С. 369. 
первоначального обвинения настолько, что оно становилось деянием, не предусмотренным обвинительным актом.

Однако указанная статья не применялась к обнаруженным на судебном следствии новым, отягчающим вину обстоятельствам, если они не изменяли сущности и свойства предусмотренного в обвинительном акте преступления, а только конкретизировали его характер.

Если в выводах обвинительного акта указывалась статья Уложения о наказаниях, не соответствующая изложенным в обвинительном акте фактическим обстоятельствам, то суд при постановке вопроса о виновности должен был принимать во внимание не ошибочно указанную статью, а фактические данные, даже если они составляли более тяжкое преступление. В таких случаях подсудимый не мог ссылаться на нарушение ст. 752 УУС, потому что он имел возможность представить свои возражения против предъявленного обвинения, основываясь не на статье уголовного закона, а на содержащихся в обвинительном акте фактических обстоятельствах.

Изменение на судебном следствии первоначально предъявленного подсудимому обвинения, если в результате этого для него усиливалась уголовная ответственность таким образом, что вопросы ставились не по первоначальному обвинению, а по изменившимся обстоятельствам, влекло за собой возникновение для суда обязанности предупредить подсудимого, что он может подвергнуться ответственности большей, чем та, которая предусмотрена обвинительным актом, и соблюдение этой обязанности фиксировалось в протоколе судебного заседания. Если в протоколе отсутствовала соответствующая запись, а вопросы ставились по новым обстоятельствам, то это рассматривалось как нарушение судом установленного законом порядка постановки вопросов и вело к отмене приговора по жалобе подсудимого. Но подобное упущение суда, не повлекшее ухудшения положения подсудимого, не являлось поводом к отмене приговора;

б) когда на судебном следствии обнаруживались обстоятельства, которые не устанавливали совершение подсудимым нового преступления, а лишь квалифицировали вину по первоначальному обвинению.

По подобным обстоятельствам могли быть поставлены в соответствии со ст. 755 УУС частные вопросы;

в) когда на судебном следствии обнаруживались обстоятельства, смягчающие вину подсудимого.

Суд не мог отказать подсудимому в постановке вопроса об обстоятельствах, по которым либо содеянное не вменялось ему в вину, либо уменьшалось наказание, либо подсудимый совсем освобождался от наказания, если такие обстоятельства были предусмотрены действующим законодательством.

Если подсудимый признавал себя виновным в преступлении менее тяжком, чем то, которое было указано в обвинительном акте, то отказ суда в постановке условного вопроса о виновности в этом преступлении, при оправдании по вопросу, поставленного по обвинительному акту, являлся существенным нарушением УУС, а вынесенный приговор подлежал отмене в кассационном порядке по представлению прокурора.

Несколько иной точки зрения о возможности изменения или дополнения на судебном следствии выводов обвинительного акта придерживался Н.А. Буцковский. Он считал, что это возможно: в отношении к лицу обвиняемого; в отношении к свойству преступления; и, наконец, в отношении к совокупности преступлений ${ }^{88}$.

а) Изменение в отношении к лицу обвиняемого.

Если на судебном следствии открывалось, что преступление, инкриминируемое подсудимому, было совершено другим лицом, то это новое лицо не могло быть привлечено к уголовной ответственности по первоначальному обвинительному акту, поскольку этот акт к нему не относился, и ему не было предоставлено возможности использовать все предусмотренные законом средства защиты. В таких случаях подсудимый оправдывался, а дело обращалось к новому производству в отношении лица, возбудившего против себя обоснованное обвинение.

Также на судебном следствии могло быть обнаружено, что подсудимый совершил преступление совместно с соучастниками, которые не упоминались в обвинительном акте. Тогда уголовное дело рассматривалось в отношении одного подсудимого, без привлечения иных лиц, лишь при наличии следующих условий:

- обстоятельства дела, касающиеся подсудимого, являлись достаточно ясными для участников уголовного судопроизводства;

- соучастники неизвестны или не обнаружены. Но при отсутствии хотя бы одного из этих условий дело возвращалось на дополнительное расследование, поскольку по общему правилу все участники преступления должны были быть судимы в рамках одного процесса (ст. 207 и 516 УУС).

б) Изменение в отношении к свойству преступления.

8 Буцковский Н.А. О приговорах по уголовным делам, решаемым с участием присяжных заседателей. С. - П., 1866. C. 35 . 
По мнению Н.А. Буцковского, необходимо было различать изменение обвинения в его существенных фактах, определяющих род преступления, и изменение сопровождающих эти факты обстоятельств, от которых зависели только вид или степень виновности ${ }^{99}$.

Во втором случае подсудимый не мог ходатайствовать о проведении дополнительного расследования, поскольку, во-первых, у него была возможность подготовить свою защиту, а во-вторых, в соответствии со ст. 734 УУС ему было предоставлено право просить о приостановлении судебных прений для предоставления возражений против новых, предъявленных на судебном следствии доказательств.

Изменение же существенных признаков преступления могло повлечь за собой нарушение гарантированного подсудимому права на защиту, поскольку появлялось новое дело, которое не подлежало рассмотрению по первоначальному обвинительному акту, расходящемуся с ним в своей основе. Поэтому в таких случаях суду предоставлялось право решать, возможно ли вынесение приговора без проведения дополнительного расследования и ограничения подсудимого в средствах защиты. И если это оказывалось невозможным, то суд должен был, не приступая к рассмотрению дела, получить разрешение судебной палаты на обращение его к новому производству (ст. 549 УУС).

в) Изменение в отношении к совокупности преступлений.

Данный случай изменения в судебном заседании выводов предварительного следствия совпадает с указанным М.В. Духовским (когда обнаруживается преступное деяние, не предусмотренное в обвинительном акте). Однако Н.А. Буцковский выводил из общего правила применения ст. 752 УУС одно исключение, связывая его не с конкретными положениями уголовно-процессуального закона, а с его общим смыслом и толкованием.

Автор считал, что не следует откладывать разрешение дела в отношении дополнительного обвинения, которое никаким образом не сможет повлиять на уголовную ответственность подсудимого. Кроме того, не согласовывалось с УУС перенесение судебного заседания и в тех случаях, когда из-за недостаточности доказательств, собранных по первоначальному обвинению, получало подтверждение обвинение дополнительное.

Поэтому Н.А. Буцковский предлагал ставить перед присяжными заседателями вопрос по дополнительному обвинению условно, после

Там же. С. 36. основного вопроса о виновности в соответствии с первоначально предъявленным обвинением, с обязательным указанием того, что этот вопрос подлежит разрешению, если подсудимый будет признан виновным в преступлении, предусмотренном в обвинительном акте. В противном случае возникшее на судебном следствии новое обвинение должно было быть направлено для производства самостоятельного и независимого от первоначального обвинения расследования в установленном законом порядке.

Но если в результате появления в судебном заседании дополнительного обвинения незамедлительное разрешение уголовного дела по существу становилось невозможным и лишало стороны надлежащих прав и гарантий, однако суд, несмотря на это, продолжал рассмотрение дела и выносил приговор, то такие действия являлись нарушением УУС и влекли за собой отмену принятого решения.

Кроме того, обнаружение в суде совокупности преступлений не препятствовало разрешению дела, если по новому преступлению не было соучастников и не заявлялся гражданский иск (ст. 515 УУС). Когда же дополнительное обвинение не отвечало указанным требованиям, дело не могло рассматриваться ни безотлагательно по обоим обвинениям, ни в отдельном производстве, а подлежало направлению на досудебную стадию для расследования по совокупности преступлений.

Суд приступал к постановке вопросов, подлежавших разрешению присяжными заседателями, по окончании судебного следствия и заключительных прений сторон (ст. 750 УУС).

Вопросы должны были устанавливать личность подсудимого и конкретный состав преступления, за которое он привлекался к уголовной ответственности. Личность подсудимого следовало определять как в судебном приговоре, т.е. с указанием его звания, имени, отчества, фамилии или прозвища и даты рождения. В тех случаях, когда особое значение имела профессия подсудимого, то устанавливались и род его занятий, ремесло, мастерство или промысел. Для определения конкретного состава преступления необходимо было указывать: место и время совершения преступного деяния; физическое или юридическое лицо, против которого это деяние было направлено, и отношение к нему подсудимого; фактический состав преступления из его законных признаков (это являлось для подсудимого единственной гарантией того, что он будет осужден за деяние, запрещенное уголовным законом под страхом наказания). При этом указывались те признаки, которыми инкриминируемое подсудимому преступление отличалось от однород- 
ных преступных деяний; и если закон не содержал точного определения этого преступления, то отличительные его признаки должны были быть определены путем сравнения его с другими пограничными составами.

Вопросы, поставленные присяжным заседателям, должны были охватывать все обстоятельства, подлежащие их обсуждению и разрешению, чтобы приговор суда основывался на точном смысле ответов присяжных безо всякого дополнения или ограничения в отношении того, что касалось фактической стороны дела. Всякое сомнение, вытекавшее из неполноты вопросов, толковалось в пользу подсудимого.

Суд должен был формулировать вопросы с той ясностью и полнотой, которая гарантировала точное определение из ответов присяжных степени участия подсудимого в совершенном преступлении. Поэтому в вопросах указывалось, в чем конкретно выражались действия подсудимого, что особенно необходимо было при участии в преступном деянии нескольких лиц.

Согласно ст. 760 УУС вопросы предлагались присяжным заседателям в общеупотребительных выражениях по существенным признакам преступления и виновности подсудимого, а не в виде принятых в законе определений. Однако эта норма не запрещала суду употреблять в вопросах выражения, использованные в законе, если они содержали термины, которые понятны для всех и которые в разговорном языке имели то же значение, что им придавал и закон. Кроме того, юридические термины могли быть заменены другими выражениями, понятными присяжным заседателям. Не рассматривалось в качестве нарушения ст. 760 УУС и изложение в вопросе после юридического термина фактических обстоятельств дела, разъясняющих его значение. Употребление в условном вопросе, поставленном присяжным заседателям, юридических терминов, если этот вопрос, при разрешении главного, оставался без ответа, также не являлось основанием для отмены приговора.

Помимо формулирования вопросов в общеупотребительных выражениях УУС в ст. 756 содержал указание на то, что не следует соединять такие вопросы, один из которых может быть разрешен утвердительно, а другой отрицательно.

Признавалось нарушением данной статьи соединение в одном вопросе:

1) признаков разных преступлений, в отношении которых присяжные заседатели могли дать противоположные ответы;

2) признаков деяния, составляющего предмет обвинения, с обстоятельствами, уменьшающими или увеличивающими степень винов- ности подсудимого, о которых должен был быть поставлен частный вопрос;

3) вопроса о виновности и о том, остановлен ли был подсудимый в совершении преступления независящими от него обстоятельствами;

4) двух обвинений, которые влекли за собой разные последствия, если присяжные давали один утвердительный ответ, не указав, какое конкретно обвинение они разрешили утвердительно.

Однако допускалось соединение судом в одном вопросе двух преступных деяний, которые хоть и различались по своей наказуемости, но имели между собой неразрывную связь и были направлены на достижение одной цели. Указание в одном вопросе двух обстоятельств, из которых одно могло быть разрешено утвердительно, а другое отрицательно, не имело значение по тем деяниям, в которых каждое из этих обстоятельств в отдельности составляло, само по себе, существенный признак преступления и влекло за собой одинаковое наказание. Кроме того, соединение в один вопрос двух отдельных преступлений не влекло отмены приговора, если присяжные заседатели в своем ответе точно указывали, какое из двух обвинений они разрешают утвердительно, или если присяжные признавали подсудимого виновным по всем обвинениям.

Вопросы присяжным заседателям излагались судом письменно, зачитывались вслух и могли изменяться или дополняться по замечаниям сторон или кого-либо из присяжных заседателей, если суд признавал такие замечания уважительными. В случае заявления требования стороной или присяжным заседателем суд давал им время обдумать свои возражения и вручал список вопросов (ст. 762 УУС).

Присяжные не должны были мотивировать свое ходатайство об изменении или дополнении представленных им вопросов. Однако данное правило не распространялось на стороны по делу. Если сторона просила суд изменить вопросы, то она должна была указать те факты судебного следствия, на которых основывалось ее требование. Если же защитник, заявляя ходатайство на основании ст. 762 УУС, не объяснял, какое оно может иметь значение для подсудимого, то отказ суда в изменении или дополнении вопросов не являлся процессуальным нарушением, влекшим за собой отмену приговора.

Ходатайства сторон разрешались постановлением суда, которое либо выносилось в виде отдельного документа, либо заносилось в протокол судебного заседания. В постановлении должны были быть изложены основания, по которым суд отказывает в удовлетворении хо- 
датайства или удовлетворяет его, но не могли предрешаться фактические вопросы, входившие в исключительную компетенцию присяжных заседателей.

В протокол судебного заседания в обязательном порядке заносились также доводы и соображения сторон, касавшиеся сформулированных судом вопросов. Новая же редакция вопросов, которую предлагали стороны, фиксировалась в протоколе только в том случае, если сторона заявляла такое требование.

Прокурор, как представитель обвинительной власти, наделялся правом опровергать доводы и соображения противной стороны. Однако он не мог обжаловать отказ суда в постановке вопроса, если данный отказ касался ходатайства, заявленного защитником.

Если же сторона своевременно не использовала предоставленное ей право просить об изменении или дополнении вопросов (когда такое изменение или дополнение было возможно), то она тем самым лишала себя возможности ссылаться в кассационной жалобе (или протесте) на неудовлетворительную редакцию вопросов. Однако оставление стороной без замечаний поставленных судом вопросов не лишало ее права ходатайствовать об отмене приговора суда и вердикта присяжных во всех тех случаях, когда вопросы были поставлены настолько неправильно, неполно или неопределенно, что вызвали неправиль- ный, неполный или неопределенный ответ присяжных заседателей.

Выслушав замечания сторон и присяжных заседателей и исправив по ним, в случае необходимости, предложенные вопросы, суд излагал их в окончательном виде на отдельном вопросном листе, который подписывался как председательствующим, так и остальными членами суда. Сформулированный и подписанный вопросный лист, по общему правилу, не мог более быть изменен или исправлен.

Исключения из этого правила дореволюционное законодательство не знало до 15 мая 1886 года. Закон от 15 мая 1886 года, приняв во внимание, что сомнения по поставленным вопросам могут появиться у присяжных заседателей и во время их совещания, предоставил им право в этом случае возвращаться в зал судебного заседания, высказывать свои сомнения и ходатайствовать перед судом о новом исправлении или дополнении уже сформулированного и врученного им вопросного листа (ст. 808 УУС). Измененные таким образом вопросы излагались на особом листе.

После составления вопросного листа в окончательной редакции председательствующий произносил перед присяжными заседателями свое заключительное объяснение (резюме), вручал старшине присяжных подписанный вопросный лист, и коллегия заседателей удалялась в совещательную комнату для вынесения вердикта.

\section{Библиография}

1. Буцковский Н.А. О приговорах по уголовным делам, решаемым с участием присяжных заседателей. С. - П., 1866.

2. Духовский М.В. Русский уголовный процесс. М., 1902.

3. Миттермайер К.М. Уголовное судопроизводство Англии, Шотландии и Северной Америки. М., 1864.

4. Радутная Н.В. Суд присяжных (исторические, социальные и правовые аспекты): Учебное пособие. М., 1991.

5. Фойницкий И.Я. Курс уголовного судопроизводства. - С. - П.: Издательство «АЛЬФА», 1996. В 2 т. Т. 2.

\section{References}

1. Butskovskii N.A. O prigovorakh po ugolovnym delam, reshaemym s uchastiem prisyazhnykh zasedatelei. S. - P., 1866.

2. Dukhovskii M.V. Russkii ugolovnyi protsess. M., 1902.

3. Mittermaier K.M. Ugolovnoe sudoproizvodstvo Anglii, Shotlandii i Severnoi Ameriki. M., 1864.

4. Radutnaya N.V. Sud prisyazhnykh (istoricheskie, sotsial'nye i pravovye aspekty): Uchebnoe posobie. M., 1991.

5. Foinitskii I.Ya. Kurs ugolovnogo sudoproizvodstva. - S. - P.: Izdatel'stvo «AL"FA», 1996. V 2 t. T. 2.

Материал поступил в редакцию 11 февраля 2014 г. 